\title{
The reliability of an extrapolated measure of an aversive threshold of pain from radiant stimulation
}

\author{
DONALD J. DILLON \\ New York State Psychiatric Institute, 722 West 168th Street, New York, New York 10032
}

\begin{abstract}
The relationship between the logarithm of pain threshold latency (sec) and the logarithm of the stimulus intensity $\left(\mathrm{mcal} / \mathrm{cm}^{2} / \mathrm{sec}\right.$ ) has been shown to be linear, and the extrapolated $\mathrm{x}$-intercept value of the linear equation could be a useful measure in pain research. In order to assess the reliability of the $x$-intercept, pain latency thresholds were obtained from $23 \mathrm{Ss}$ by utilizing the D'Amour-Smith modification of the dolorimetric technique and by testing under a variety of conditions at each of four stimulus intensities. The empirically determined $\log t$ (sec) values were shown to be slightly, but significantly, higher when stimulation was applied to either the dominant limb or to the legs rather than to the nondominant limb or to the arms. The computed slope and $x$-intercept values did not differ between limbs or between dominant and nondominant sides. None of the three measures changed significantly between the two sessions. The $\mathrm{x}$-intercept value was interpreted as an index of a threshold of aversion and its meaning and applicability were discussed.
\end{abstract}

Individuals differ markedly in their reactions (sensitivity) to painful stimulation. For example, Clausen and King (1950) reported a range of threshold values for radiant stimulation of 170 to $372 \mathrm{mcal} / \mathrm{cm}^{2} / \mathrm{sec}$. Dillon (1968), also using radiant stimulation, showed that Ss tended to cluster in three more or less separate groups, and that, on the average, the Ss in the least sensitive group displayed energy thresholds $50 \%$ greater than Ss in the most sensitive group. Petrie (1967) points up the extent of and the meaning of individual differences by classifying individuals as (pain) augmenters and (pain) reducers.

Threshold variations within individuals have also been reported (Hardy, Wolff, \& Goodell, 1953; Dillon, 1968). Wolff and Jarvik (1964) and Wolff, Kantor, Jarvik, and Laska (1966) have reported that the right (dominant) side of the body is less sensitive to both electrical and cold pressor stimulation.

Beecher (1959) and Barber (1963) argue that these individual differences stem from the emotional or reactive component of the pain response. Clark (1969) argues that, by utilizing the method of signal detection theory, one can derive separate and independent measures of the two components of the pain response: $\mathrm{d}^{\prime}$, representing the sensory components, and $\mathrm{L}_{\mathbf{x}}$. indicating the emotional component or attitude towards pain.

This reactive component would seem to be the source of the difficulties involved in the laboratory investigation of pain. The laboratory procedures involve pain at the perceptual (usually detection) level, and the subjective impression is one of a very minor pain-one "scarcely worth noting." The reactive component is minimal and probably (Clark. 1969) a matter of the individual's criterion (response bias) of what pain really is. On the other hand, pain arising in pathology is much more intense and more critical to the individual, who is now emotionally involved. Consequently. the contribution of the reactive component to the total pain response is greater.
Apparently, this is the reason for Beecher's (1966) feeling that rigidly controlled laboratory techniques are inadequate for the study of pain, and for his preferred utilization of ischemia. Because ischemic pain is more "painful" by virtue of its possessing more of the reactive (emotional) component, it is the technique of choice for studying pain and for generalizing from these studies to the more general type of pain in pathological or aversive situations.

The D'Amour-Smith (1941) or latency modification of the dolorimetric procedure is another laboratory procedure possessing potentially great reactive elements. Since $S$ reacts to the onset of pain by extinguishing the stimulus, the latency measurements obtained may be conceived of as reactive thresholds. Such reactions, however, are at detection levels: $S$ must extinguish the stimulus at the very moment that his perception changes from one of heat to one of pain. Dillon (1968) has shown that the latency of these reactions becomes less variant among individuals as stimulus intensity is raised, that the pain itself becomes sharper. more intense, and better localized, and Ss become more alike (and certain) as to the criterion invoked for stimulus termination. In later papers (Dillon. 1970, 1971), the Ss reported that the transition from heat to pain when stimulus intensity was at a level of $360 \mathrm{mcal} / \mathrm{cm}^{2} / \mathrm{sec}$ or greater occurred at unpleasant levels and that they would be unable to tolerate such levels of pain.

Dillon (1971) showed that pain from radiant stimulation of from 80 to $500 \mathrm{mcal} / \mathrm{cm}^{2} / \mathrm{sec}$ exhibits temporal summation. since $\log t$ (threshold latency in sec) was linearly related to $\log$ I (intensity). The two parameters (slope: $m$ and $y$ intercept: b) from the equation $\log t=m \log l+b$ were shown to be relevant to pain research. The $\mathrm{x}$-intercept, however, was substituted for $b$ since $b$ is largely uninterpretable. The $\mathrm{x}$-intercept represents the intensity which would be necessary to evoke a response latency of $1.0 \mathrm{sec}$. Such a latency would indicate a very painful reaction and, for this reason. has heen termed a threshold of aversion, and 
Table 1

Means and SDs of Pain Latency Thresholds $(\log t)$ According to Stimulus Intensity, Lateral Dominance, and Limb, Together With $\log t$ Averaged Across Dominance and Limb $\dagger$

\begin{tabular}{|c|c|c|c|c|c|c|}
\hline \multirow[b]{3}{*}{$\log _{10} I$} & & \multicolumn{4}{|c|}{ Limb } & \multirow[b]{3}{*}{$\begin{array}{c}\text { Overall } \\
\text { Average }\end{array}$} \\
\hline & & \multicolumn{2}{|c|}{. Arm } & \multicolumn{2}{|c|}{ Leg } & \\
\hline & & $\begin{array}{c}\text { Domi- } \\
\text { nant }\end{array}$ & Non-D & $\begin{array}{l}\text { Domi- } \\
\text { nant }\end{array}$ & Non-D & \\
\hline 2.623 & $\begin{array}{l}\text { M } \\
\text { SD }\end{array}$ & $\begin{array}{l}.387 \\
.084\end{array}$ & $\begin{array}{l}.374 \\
.110\end{array}$ & $\begin{array}{l}.396 \\
.075\end{array}$ & $\begin{array}{l}.376 \\
.078\end{array}$ & $\begin{array}{l}.383 \\
.076\end{array}$ \\
\hline 2.477 & $\begin{array}{l}M \\
\text { SD }\end{array}$ & $\begin{array}{l}.584 \\
.074\end{array}$ & $\begin{array}{l}.552 \\
.090\end{array}$ & $\begin{array}{l}.597 \\
.068\end{array}$ & $\begin{array}{l}.583 \\
.082\end{array}$ & $\begin{array}{l}.579 \\
.067\end{array}$ \\
\hline 2.301 & $\begin{array}{l}\mathbf{M} \\
\mathrm{SD}\end{array}$ & $\begin{array}{l}.821 \\
.085\end{array}$ & $\begin{array}{l}.799 \\
.080\end{array}$ & $\begin{array}{l}.842 \\
.088\end{array}$ & $\begin{array}{l}.829 \\
.080\end{array}$ & $\begin{array}{l}.822 \\
.076\end{array}$ \\
\hline 2.079 & $\begin{array}{l}\mathrm{M} \\
\mathrm{SD}\end{array}$ & $\begin{array}{r}1.133 \\
.094\end{array}$ & $\begin{array}{r}1.111 \\
.101\end{array}$ & $\begin{array}{r}1.167 \\
.095\end{array}$ & $\begin{array}{r}1.123 \\
.085\end{array}$ & $\begin{array}{r}1.133 \\
.083\end{array}$ \\
\hline $\mathrm{m}$ & $\begin{array}{l}M \\
\text { SD }\end{array}$ & $\begin{array}{r}-1.370 \\
.155\end{array}$ & $\begin{array}{r}-1.363 \\
.147\end{array}$ & $\begin{array}{r}-1.416 \\
.155\end{array}$ & $\begin{array}{r}-1.374 \\
.139\end{array}$ & $\begin{array}{r}-1.380 \\
.132\end{array}$ \\
\hline$x$ & $\begin{array}{l}\mathrm{M} \\
\mathrm{SD}\end{array}$ & $\begin{array}{r}2.911 \\
.079\end{array}$ & $\begin{array}{r}2.903 \\
.103\end{array}$ & $\begin{array}{r}2.911 \\
.069\end{array}$ & $\begin{array}{r}2.906 \\
.072\end{array}$ & $\begin{array}{r}2.909 \\
.069\end{array}$ \\
\hline
\end{tabular}

tThe linear parameters computed from $\log t=b+m \log I$ (slope: $m$ and $x$-intercept: $x$ ) are listed according to dominance and limb. Data from $23 \mathrm{Ss}$.

*Intensity' $=\mathrm{mcal} / \mathrm{cm}^{2} / \mathrm{sec}$.

consequently would include a large reactive component. Thus, it would be possible to approximate a pathological condition by extrapolating from pain data obtained under precise laboratory conditions.

This investigation was undertaken in order to determine the degree to which these two parameters-slope and $x$-intercept-are repeatable when latency thresholds are obtained from a group of naive Ss.

\section{METHOD}

\section{Subjects}

Latency thresholds for pricking pain were obtained from 1 ambidextrous, 5 left-handed, and 17 right-handed Ss. Only one female S (right-handed) was tested. All Ss were undergraduate volunteers, and none had participated in any kind of pain research prior to this experiment.

\section{Apparatus}

The Hardy-Wolff-Goodell dolorimeter (Williamson Development Co., West Concord, Massachusetts) was employed. Calibration of the instrument, by means of a therm spile (Model ET-2) and galvanometer (both Williamson Co.), was carried out at the start of each session. The stimulus intensities employed were $120,200,300$, and $420 \mathrm{mcal} / \mathrm{cm}^{2} / \mathrm{sic}$.

A telethermometer (Yellow-Springs Co., Model 43TD) was used to measure skin temperature, which was always maintained at a level of $33.5^{\circ} \pm 0.5^{\circ} \mathrm{C}$ immediately prior to any latency determination. This instrument was also used to monitor room temperature, which was found to vary by only $2^{\circ} \mathrm{C}$ (from $23^{\circ}$ to $25^{\circ} \mathrm{C}$.

\section{Procedure}

Testing was carried out in a sound-deadened room, which measured approximately $8 \times 8 \mathrm{ft}$. E sat at the center of a desk facing the instrument, and $S$ sat at the left side of the desk facing E. In order to prevent $S$ from utilizing the light intensity as a cue to the heat intensity currently used as a stimulus, $S$ was instructed to look away from the gun-like lamp housing and projector system after placing it against his skin. He was also screened off from the instrument so that he could not see the dials.

Careful measurements of the length of the volar surfaces of the forearms from wrist to elbow and of the inner surfaces of the calves from ankle to knee were made and noted. Two spots, equidistant from each other and from these "reference points." were selected and painted thoroughly with India ink. An additional spot on the nondominant forearm was also painted. E tested this spot in order to demonstrate hot and painful stimuli to $S$ and to acquaint $S$ with the details of the experiment, especially the criterion for extinguishing the stimulus at the moment of transition from a feeling of warmth or heat to one of pain. This more or less sudden transition has been described by Zegers and Cahill (1965). S was carefully instructed to turn off the lamp at the detection of pain, i.e., he was reminded constantly that $\mathrm{E}$ was interested in pain detection and not in pain tolerance.

The distal spots on each limb were tested first, and stimulation proceeded from dominant to nondominant arm and then to dominant and then nondominant leg. The proximal spots were then tested in the same fashion. Alternation of spot, limb, and side was continued until each spot had been tested once with each of the four intensities. Every other $S$ (with the ambidextrous $S$ considered as left-handed) was started on the nondominant side, and all $S s$ reversed the dominantnondominant order in the second session, which was carried out 1 week later.

In most cases (in all, when testing leg spots), the skin had to be warmed to the desired temperature. This was accomplished by stimulation with $3.0-\mathrm{sec}$ bursts of radiation at an intensity level which was too low to elicit a pain response.

\section{RESULTS}

The latency values were transformed logarithmically and classified according to a fivefold schema of intensity, dominance, limb, session, and S. These data, averaged across session and $S$ (spots were ignored) are summarized in Table 1 . The five-way analysis of variance, in which the various appropriate interactions with $S$ were utilized as error terms, revealed, in addition to the obvious significance of intensity and $\mathrm{S}$ effects ( $87.8 \%$ and $5.1 \%$ of the total variance, respectively); that the effects of limb $(F=5.06, d f=1 / 22, p<.05)$ and of dominance $(F=4.87, \mathrm{df}=1 / 22, \mathrm{p}<.05)$ were significant. There were no statistically significant interaction effects. In addition to the obvious decrease in $\log t$ with increased $\log I$, it is clear from the data in Table 1 that Ss reacted more slowly when either the legs or the dominant side were stimulated painfully than when stimulation was applied to either the arms or the nondominant side.

The relationship between $\log t$ and $\log I$ may be said to be linear, since the regression of $\log t$ upon $\log I$ still accounts for $87.7 \%$ of the total variance. The parameters of this equation have also been summarized in Table 1 . Analyses of variance of $m$ and $x$ revealed no significant effects other than individual differences (Ss accounted 
for $57.5 \%$ and $59.2 \%$ of the variances in $\mathrm{m}$ and $\mathrm{x}$, respectively). Thus, while the latency (reactive) thresholds vary significantly with the limbs and with lateral dominance, the aversive threshold does not exhibit such significant variation. One might also note the low value of $\mathrm{SD}(\mathrm{x})$ in the average column.

The $\log t, m$, and $x$ values were averaged across the four bodily areas for each intensity and each session, and Pearson correlation coefficients computed between sessions. These Pearson $r$ values, listed in Table 2, were all highly significant $(p<.01)$. Although the $r$ values are highest for $m$ and especially $x$, these were not significantly greater than the $r$ values for any given $\log t$.

\section{DISCUSSION}

The fact that the nondominant limb is slightly but significantly more sensitive to painfully radiant stimulation than the dominant limb confirms the results presented by Wolff and Jarvik (1964). The sensitivity differences between arms and legs would be an extension of these and of Dillon's findings (1968) that sensitivity varies along the volar surface of the forearm. One must note, however, that these differences barely attained a level of statistical significance $(p<.05)$, and that the limb and dominance differences each contributed only $0.1 \%$ to the total variance in $\log t$. One can only conclude that these variables would probably play no more than a secondary role in determining sensitivity to painfully radiant stimulation.

The slope (m) values would not be expected to vary significantly with either limb or dominance, since the interaction of limb with intensity or intensity with dominance did not produce significant effects upon $\log \mathrm{t}$.

Since the $m$ values did not vary with limb or dominance, and sincè the $\log t$ values did. one would expect the same degree of significance of sensitivity differences in $x$ across these four body areas. The lack of significant effects can be traced to two sources. Each variable contributed only 0.1 to the total variance in $x$. and, in this case, the estimates of error variance (the Limb by $\mathrm{S}$ and/or the Dominance by $\mathrm{S}$ interaction terms) were quite large ( 10 to 20 times as great as their counterparts for $\log t$ in terms of percent of total variance). It is possible that lower estimates of error variance should have been employed but no other estimates are appropriate with this type of design.

This investigation has demonstrated the repeatability of the $x$-intercept values. The designation of $x$ as an index of an aversive threshold still seems to be appropriate, since the $S$ continue to attest to the unpleasantness of high-intensity stimulation $\left(420 \mathrm{mcal} / \mathrm{cm}^{2} / \mathrm{sec}\right.$, in this case).

The antilog of $x$. of course. represents the stimulus intensity which would be necessary to evoke from $S$ a pain response latency of $1.0 \mathrm{sec}$. a value strikingly similar to the RT for touch pain (with pain as the only
Table 2

Pearson Product-Moment Correlation Coefficients (All +) Between Sessions 1 and 2, Listed for Slope (m) and x-Intercept $(x)$, and According to Stimulus Intensity $(\log 1)$ for 23 Ss

\begin{tabular}{cccccc} 
& \multicolumn{2}{c}{$\log _{10} \mathrm{I}$} & & $\mathrm{m}$ & $\mathrm{x}$ \\
\hline 2.079 & 2.301 & 2.477 & 2.623 & 0.791 & 0.845 \\
0.695 & 0.748 & 0.732 & 0.758 & 0.791 & 0.845 \\
\hline
\end{tabular}

feeling) found by Eichler and cited by Woodworth and Schlosberg (1954). It would be most interesting if one could extrapolate to a thermal or radiant $\mathrm{RT}$ for radiant pain from the $\log t \log I$ curve, and if a more sensitive statistical test (different error term) could be utilized to test for the limb and dominance differences in both $\mathrm{x}$ and $\mathrm{m}$. It is quite possible that the greater sensitivity on the part of the nondominant side and of the arms as reported here can be attributed to differences in RT to pain. The Ss were less comfortable when holding the lamp housing (a gun-like device) in the nondominant hand and when holding it against the legs, and could be expected to react more slowly in terminating the stimulus.

The latency modification of dolorimetry makes use of reactions to painfully radiant stimulation, and the pain can be sudden, sharp, and unpleasant. Since the relationship between $\log$ latency and $\log$ stimulus intensity is linear, one can extrapolate to what is considered a threshold of aversion (the $x$-intercept). This is a reliable measure which should prove useful in the laboratory study of pain.

\section{REFERENCES}

Barber, T. X. The effects of "hypnosis" on pain: A critical review of experimentai and clinical findings. Psychosomatic Medicine. 1963. 24. 303-333.

Beecher. H. K. Measurement of subjective responses: Quantitative effects of drugs. New York: Oxford University Press. 1959.

Beecher. H. K. Pain: One mystery solved. Science. 1966, 151, 840-841.

Clark. W. C. Sensory-decision theory analysis of the placebo effect on the criterion pain and thermal sensitivity (d'). Journal of Abnormal Psychology. 1969. 74. 363-371.

Clausen. J.. \& King. H. E. Determination of pain threshold on untrained subjects. Journal of Psychology, 1950. 30. 299-306.

D'Amour. F. E.. \& Smith. D. L. A method for determining loss of pain sensation. Journal of Pharmacology \& Experimental Therapeutics, 1941, 72. 74-79.

Dillon. D. J. Stimulus intensity. site of stimulation. and individual reactivity as determinants of the energy threshold for pricking pain. Journal of Experimental Psychology, 1968, 77. 559.566 .

Dillon. D. J. Changes in the relationship between threshold latency and stimulus intensity in the perception of pricking pain. Proceedings of the American Psychological Association, 1970. $5.37-38$.

Dillon. D. J. Temporal summation of pain from radiant stimulation. Perception \& Psychophysics, 1971. 10. 109-111.

Dillon. D. J. A moditicd dolorimeter technique for analgesic studies. Paper read at the annual convention of the American Pisuchological Ariociation. Honolulu, Hawaii. September 6 , 1972 
Hardy, J. D., Wolff, H. G., \& Goodell, H. Pain sensations and reactions. Baltimore: Williams \& Wilkins, 1952.

Petrie, A. Individuality in pain and suffering. Chicago: University of Chicago Press. 1967.

Wolff, B. B., \& Jarvik, M. E. Relationship between superficial and deep somatic thresholds of pain with a note on handedness. American Journal of Psychology, 1964, 77, 589-599.

Wolff, B. B., Kantor, T. G., Jarvik, M. E., \& Laska, E. Response of experimental pain to analgesic drugs. I. Morphine, aspirin, and placebo. Clinical Pharmacology \& Therapeutics, 1966, 7, 224-238.

Woodworth, R. S., \& Schlosberg, H. Experimental psychology. New York: Holt, Rinehart, \& Winston, 1954.

Zegers, R. T., \& Cahill, M. C. The latency of pricking-pain sensation: I. The effect of acetophenetidin and Anacin. II. The effect of repeated stimulation. Journal of Psychology, $1965,59,101-108$.

(Accepted for publication February 6, 1973.) 